\title{
THE REMOVAL OF REACTIVE RED 141 FROM WASTEWATER: A STUDY OF DYE ADSORPTION CAPABILITY OF WATER-STABLE ELECTROSPUN POLYVINYL ALCOHOL NANOFIBERS
}

\author{
Çigdem Akduman¹, Seniha Morsümbül², Emriye Perrin Akçakoca Kumbasar², \\ 1 Denizli Vocational School of Technical Sciences, Department of Textile Technology, Pamukkale University, 20100 Denizli, Turkey \\ 2 Faculty of Engineering, Department of Textile Engineering, Ege University, 35100 Izmir, Turkey \\ *Correspondence to: perrin.akcakoca@ege.edu.tr
}

\begin{abstract}
:
The dye production and its use in textile and related industries resulted in discharge of dye to wastewater. Adsorption for color removal is known as equilibrium separation process, and the resultant decolorization is influenced by physicochemical factors such as adsorbent surface area. The nanofiber membranes prepared by the electrospinning method have controllable nanofiber diameter and pore size distribution (PSD) with a high surface area to volume or mass ratio. In this study, polyvinyl alcohol (PVA) nanofibrous membranes were prepared by the electrospinning method at different collection times such as 3, 5 and $10 \mathrm{~h}$ and heat fixated at 130,150 and $170^{\circ} \mathrm{C}$ for $10 \mathrm{~min}$, and then, the adsorption capability of PVA nanofiber membranes for Reactive Red 141 from aqueous solution was investigated. In order to make PVA nanofibers stable to water, the nanofibrous membranes were chemically crosslinked by a polycarboxylic acid (1,2,3,4 butanetetracarboxylic acid (BTCA)). PVA nanofibrous membranes were characterized by scanning electron microscopy, thermogravimetric analysis, swelling tests and pore size analysis. The results indicated that BTCA crosslinking improved the thermal and water stability of the nanofibrous structure but has no significant effect on the pore sizes of the membranes. Adsorption of Reactive Red 141 was studied by the batch technique, and it was observed that PVA nanofibers removed approximately $>80 \%$ of the dye.
\end{abstract}

\section{Keywords:}

Reactive dye, textile wastewater, decolorization, electrospinning, pore size

\section{Introduction}

The world dyes and pigments market was estimated at USD 30.42 billion in 2016 [1]. More than 100,000 commercial dyes are available with over 700,000 tons of production annually [2] of which $50 \%$ are textile dyes [3]. The dye production and its use in textile and related industries resulted in discharge of dyes to wastewater. It is estimated that a loss of $1-2 \%$ in dye production and $1-10 \%$ in use and in total $10-15 \%$ of the dyes are discharged as effluent from these industries [2, $4,5]$. Wastewater from the textile dyeing process contains approximately $8-20 \%$ dyes of the total pollution load due to incomplete exhaustion of the dyes [2, 6]. Moreover, it is known that more than half of the market size belongs to reactive dyes [1]. In reactive dyeing, unfixed or hydrolyzed reactive dyes have to be washed off thoroughly in order to achieve the desired superior wet fastness. The major cost of a reactive dyeing process could be attributed to the washing-off stages [7]. The main problem about reactive dye effluent is that reactive dyes have very small tendency of being absorbed on the sludge due to their high solubility in water [8]. As a result, they pass through the purification plant and are released into the environment. Thus, lots of researches have been undertaken in order to develop an effective treatment process for color removal of reactive dyes.
A wide range of technologies could be used for color removal of the synthetic dyes from wastewaters to decrease their impact on the environment. These technologies could be divided into three categories such as chemical, biological and physical. Physical methods that include adsorption, ion exchange, filtration and membrane-filtration processes (nanofiltration, reverse osmosis and electrodialysis) are widely used in industry because of their dye removal potentials and low operating costs [2]. Among these techniques, adsorption is known as equilibrium separation process, and generally, it does not result in the formation of harmful substances [9-11]. Adsorption has many advantages such as low initial cost, flexibility and simplicity of design, ease of operation and insensitivity to toxic pollutants. Adsorption and resultant decolorization are influenced by physicochemical factors such as dye/adsorbent ratio, adsorbent surface area, particle size, temperature, $\mathrm{pH}$, and contact time.

Adsorption occurs by the interaction between the adsorbate and the molecules in the fluid phase. There are two kinds of forces that bring about to either physical adsorption (physisorption) or chemical adsorption (chemisorption) [12]. Physical adsorption occurs between the adsorbate and the adsorbent reversibly via weak interactions, such as Van der Waals interactions, hydrogen bonding and dipole-dipole interaction. Chemical adsorption occurs irreversibly via strong interactions, such as covalent and ionic bond formation, between the adsorbate and 
the adsorbent [2]. The attractive forces between the adsorbent and the adsorbate are influenced by the properties of the adsorbent such as structure, surface area, chemical nature and polarity of the adsorbent [13].

Activated carbon [11, 12], clay [14], biomass [15], agricultural solid wastes [16] and nanofibers [14, 15] have generally been used as adsorbents in the adsorption studies. Among these adsorbents, the nanofiber membranes prepared by the electrospinning method have unique properties such as controllable nanofiber diameter, PSD and orientation at a lower cost. The process has attracted a great deal of attention due to its relative ease of use, adaptability [16, 17], lots of possibilities for surface functionalization $[18,19]$ with a high surface area to volume or mass ratio, small interfibrous pore size and high porosity [17, 20, 21]. These properties have led electrospun nanofiber membranes to be used for the removal of heavy metal ions [22-24] and dye molecules from textile wastewater $[25,26]$

A wide variety of polymers such as polyethylene oxide [13] chitosan [10, 27], polyacrylonitrile [28], cellulose acetate [29] and polyvinyl alcohol (PVA) [28-30] have been used in the studies of wastewater treatments. Apart from these studies, in the present contribution, to the best of authors' knowledge, porosity comparison of the PVA nanofibers and the effect of fixation temperature and collection period on chemically crosslinked and water-stable PVA nanofibers have been investigated for their reactive dye removal from wastewater for the first time.

PVA is a water-soluble polyhydroxy polymer and has excellent chemical resistance and physical properties along with complete biodegradability, which leads to broad practical applications. In the case of colored textile wastewater, these membranes can be used for both filtration and dye adsorption purposes, which allows the removal of submicron particles and as well as the removal of color from wastewater. PVA nanofiber mats could be prepared by the electrospinning of the aqueous PVA solutions and could be cross-linked with chemical crosslinking agents [31]. In this study, to make PVA nanofibers stable to water and decrease their swelling characteristics in water, they were chemically cross-linked by a polycarboxylic acid $(1,2,3,4$ butanetetracarboxylic acid (BTCA)). The effects of heat fixation
(130, 150 and $170^{\circ} \mathrm{C}$ ) and collection period on adsorption capacities of PVA and BTCA cross-linked PVA nanofibers were compared.

Most of industrial adsorbents have large specific surface areas and are therefore highly porous or consist of very fine particles [12]. Nanofiber-based mediums have low basis weight, high permeability and small pore size that make them also appropriate for a wide range of applications. In order to compare the porosity of produced nanofiber membranes, the pore size measurement performed for 3,5 and $10 \mathrm{~h}$ collected neat-PVA and PVA-BTCA nanofiber membranes. The produced PVA nanofiber membranes were finally evaluated for the color removal of Reactive Red 141 from aqueous solution.

\section{Experimental}

\subsection{Materials}

PVA with an average molecular weight of $125,000 \mathrm{~g} / \mathrm{mol}$, BTCA, sodium hypophosphite monohydrate: $\left(\mathrm{NaPO}_{2} \mathrm{H}_{2} \cdot \mathrm{H}_{2} \mathrm{O}\right)$, sodium sulfate $\left(\mathrm{Na}_{2} \mathrm{SO}_{4}\right)$ and sodium carbonate $\left(\mathrm{Na}_{2} \mathrm{CO}_{3}\right)$ were purchased from Sigma Aldrich Chemical Company. The dye, C.I. Reactive Red 141, was supplied from DyStar and used as received. The chemical structure of the dye is illustrated in Figure 1.

\subsection{The preparation of electrospinning solutions}

A weighed amount of PVA was dissolved in distilled water at $100^{\circ} \mathrm{C}$ to prepare an aqueous PVA stock solution at a fixed concentration of $10 \% \mathrm{w} / \mathrm{w}$. BTCA as a crosslinking agent was selected to be $5 \%\left(\mathrm{w} / \mathrm{w}_{\text {polymer }}\right)$ and was directly added into the spinning solution with sodium hypophosphite monohydrate as a catalyst in the ratio of $2: 1(\mathrm{w} / \mathrm{w})$ followed by stirring for $15 \mathrm{~min}$. As a control, neat-PVA nanofibers were also prepared by electrospinning.

\subsection{Electrospinning}

Electrospinning of the polymer solutions was carried out by a setup consisting of a syringe $(10 \mathrm{ml})$ with a stainless steel

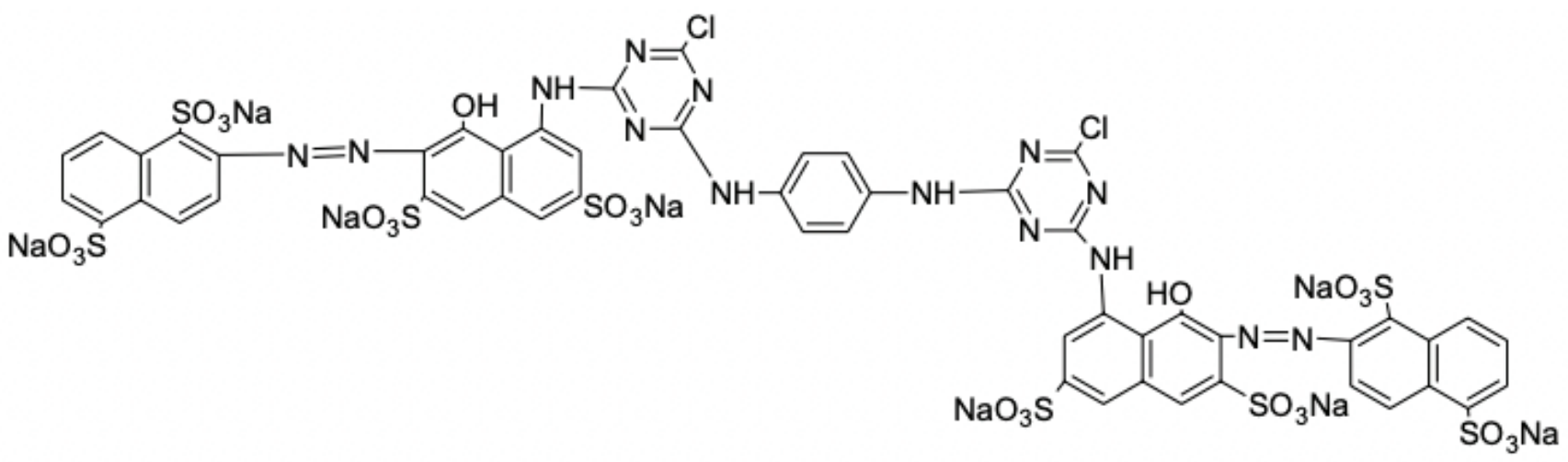

Figure 1. Chemical structure of Reactive Red 141 [8]. 
needle (22 gauges and flat tip), a ground electrode and a high-voltage supply (Simco, MP Series CM5 30 P, Charging Generator Output $30 \mathrm{kV}$ DC). A grounded rotating metal drum collector covered by a 90 mesh of plain weave monofilament of $100 \%$ polyester screen mesh fabric was used as deposition material. Neat-PVA and PVA-BTCA solutions were electrospun for 3, 5 and $10 \mathrm{~h}$. After electrospinning, the nanofibers were heat fixated at different temperatures such as 130, 150 and $170^{\circ} \mathrm{C}$ for $10 \mathrm{~min}$ and coded as PVA-130, PVA-150, PVA170, PVA-BTCA-130, PVA-BTCA-150 and PVA-BTCA-170. All electrospinning experiments were performed at room temperature $\left(22 \pm 2^{\circ} \mathrm{C}\right)$, where the relative humidity was 22 $40 \%$.

\subsection{Thermogravimetric analysis (TGA) of nanofibrous mats}

TGA (Perkin Elmer TGA-4000) of PVA and PVA-BTCA crosslinked nanofibers were carried out by heating samples from 25 to $600^{\circ} \mathrm{C}$ at a rate of $10^{\circ} \mathrm{C} / \mathrm{min}$ under continuous nitrogen purge at the rate of $20 \mathrm{ml} / \mathrm{min}$.

\subsection{Scanning electron microscope (SEM) analysis}

The electrospun nanofibers were sputtered by Quorum Q150R S ion sputtering device with a thin layer of gold prior to SEM observation. The morphology of the nanofibers was analyzed by an SEM (Phenom G2 pro).

\subsection{Measurement of thickness, weight per square meter and fiber diameters}

The thicknesses of the nanofiber mats were measured by Mitutoyo digital micrometer at $0.01 \mathrm{~mm}$ accuracy. Weights of nanofiber mats were calculated from the weights of small rectangular pieces. A total of eight and three measurements were carried out from the different parts of each sample for thickness and weight, respectively. The mean diameter of the resultant fibers was calculated from measurements on SEM images of $x 10,000$ magnification by using ImageJ program. Approximately 50 measurements were carried out from the different parts of PVA nanofiber samples. Measurements of all thicknesses, weights and fiber diameters were expressed as mean \pm SD.

\subsection{Swelling and weight loss of nanofibrous mats}

Swelling of the neat-PVA and PVA-BTCA electrospun nanofiber mats was measured upon exposure in distilled water for $24 \mathrm{~h}$. The samples were removed from the water and carefully blotted with tissue paper to remove the excess from the surface. The degree of swelling due to the water uptake was determined, and weight loss was calculated at the end after drying for $4 \mathrm{~h}$ at $70^{\circ} \mathrm{C}$ in an oven. The percentages of degree of swelling and weight loss were calculated as follows [32]:

$$
\text { Degree of swelling }(\%)=\frac{M-M_{d}}{M_{d}} \times 100
$$

and
Weight loss $(\%)=\frac{M_{i}-M_{d}}{M_{i}} \times 100$

where $M$ was the weight of each nanofiber mat sample upon exposure in distilled water for $24 \mathrm{~h}, M_{d}$ was the weight of the PVA nanofibers after swelling and subsequent drying and $M_{i}$ was the initial weight of the sample.

\subsection{Pore size measurements}

The pore size measurements of the PVA nanofiber mats were measured by capillary flow porometry (Porolux 1000, Germany). All samples were wetted by a wetting liquid with a low surface tension of $16 \mathrm{dyne} / \mathrm{cm}$ before the measurements. Mean flow pore size (MFP), first bubble point (FBP) and PSD were measured by the wet-up/dry-up method.

\subsection{Adsorption experiments}

Since the reactive dyes are the most used dye class in the textile industry, the neat-PVA and PVA-BTCA nanofiber mats were used for the adsorption of a commercial reactive dye Reactive Red 141. $\mathrm{Na}_{2} \mathrm{SO}_{4}$ and $\mathrm{Na}_{2} \mathrm{CO}_{3}$ were added to the adsorption solution in order to simulate the dyeing condition. The kinetic studies were carried out in a $15 \mathrm{ml}$ test tube containing $10 \mathrm{mg}$ adsorbent and $10 \mathrm{ml}$ of the adsorption solution with $45 \mathrm{~g} / \mathrm{l}$ $\mathrm{Na}_{2} \mathrm{SO}_{4}, 10 \mathrm{~g} / \mathrm{l} \mathrm{Na} \mathrm{CO}_{3}$ and $85 \mathrm{mg} / \mathrm{l}$ dye concentrations at $\mathrm{pH}$ 10.5-11. These tubes were stirred on an orbital shaker (Nüve, ST 402 ) at $25^{\circ} \mathrm{C}$ over a time interval of $0-48 \mathrm{~h}$. The residual dye concentration in the liquid was analyzed using a UV-Vis spectrophotometer (Perkin Elmer Lambda 25) at $518 \mathrm{~nm}$. The data were used to calculate the adsorption capacity $(\mathrm{mg} / \mathrm{g})$, $q_{e}$, of the adsorbent. The dye concentration on the adsorbent surface at equilibrium was calculated by

$$
q_{e}=\frac{\left(C_{0}-C_{e}\right) v}{m}
$$

where $C_{0}$ is the initial dye concentration in the liquid phase $(\mathrm{mg} / \mathrm{l}), C_{e}$ the equilibrium dye concentration $(\mathrm{mg} / \mathrm{l}), V$ the total volume of dye solution used (I) and $m$ the mass of adsorbent used $(g)$.

\subsection{Adsorption kinetics}

Two of the most frequently used kinetic models that are the pseudo-first-order and the pseudo-second-order kinetic models were used for the characterization of the adsorption studies.

The pseudo-first-order kinetic model is given by the following equation:

$$
\frac{d q_{t}}{d t}=k_{1}\left(q_{e}-q_{t}\right)
$$

By taking $q_{t}=0$ at $t=0$ and $q_{t}=q_{t}$ at time $t$, the integrated form of Equation 4 becomes

$$
\ln \left(\frac{q_{e}}{q_{e}-q_{t}}\right)=k_{1} t
$$


where $q_{t}$ is the amount of adsorbed dye at time $t$ and $k_{1}$ is the rate constant of first-order adsorption. The parameters of the equation can be obtained from the linear plot of $\ln \left(q_{e}-q_{t}\right)$ versus $t$.

The pseudo-second-order kinetic model is given by the following equation:

$$
\frac{d q_{t}}{d t}=k_{2}\left(q_{e}-q_{t}\right)^{2}
$$

where $k_{2}$ is the pseudo-second-order rate constant of adsorption. As in Equation 4, by taking $q_{t}=0$ at $t=0$ and $q_{t}=q_{t}$ at time $t$, the integrated form of Equation 6 becomes

$$
\frac{t}{q_{t}}=\frac{1}{k_{2} q_{e}^{2}}+\frac{t}{q_{e}}
$$

The plot of $t / q$ versus $t$ gives a straight line with a slope of $1 / k_{2} q_{e}^{2}$ and an intercept of $1 / q_{e}[14]$.

\section{Results and discussion}

\subsection{TGA of heat-fixated neat and BTCA cross-linked} electrospun PVA nanofibers

In Figures 2-4, the TGA thermograms of $10 \mathrm{~h}$ produced neatPVA and heat-fixated PVA nanofibers with and without BTCA are given according to fixation temperature. In these curves, the electrospun neat-PVA nanofibers lost $\sim 7 \%$ mass at temperatures up to $100^{\circ} \mathrm{C}$ due to the evaporation of absorbed moisture. The decomposition of neat-PVA began around $270^{\circ} \mathrm{C}$ and lost half of its mass at $330^{\circ} \mathrm{C}$, leaving merely $\sim 2 \%$ residue at $600^{\circ} \mathrm{C}$. Neat-PVA nanofi bers had two degradation steps: the elimination reactions started at $\sim 225^{\circ} \mathrm{C}$ and the breakdown of the polymer backbone (mostly chain-scission reactions) started at $\sim 374^{\circ} \mathrm{C}$ as a second stage (residue weight: $\sim 83 \%$ and $\sim 28 \%$, respectively) (Table 1) [33]. The temperatures of elimination reactions were approximately at 281, 269 and $262^{\circ} \mathrm{C}$ and the chain-scission reactions were approximately at 477,468 and $461^{\circ} \mathrm{C}$ for PVA-130, PVA-150 and PVA-170

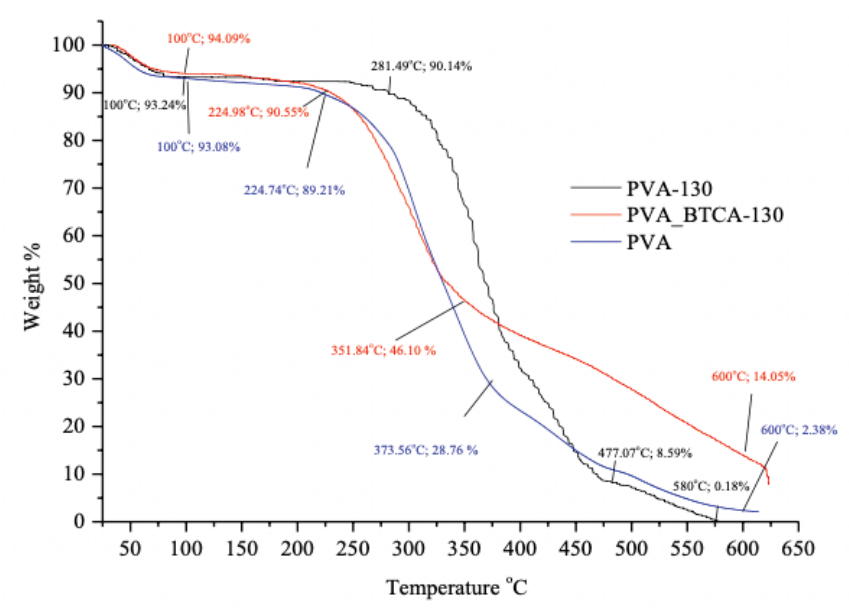

Figure 2. TGA thermograms of $10 \mathrm{~h}$ produced neat-PVA, PVA-130 and PVA-BTCA-130 nanofibers. nanofibers, respectively. The starting point of elimination reaction almost stayed same, but heat fixation significantly increased the starting temperature of chain-scission reaction due to self-crosslinking with heat. This showed that heat crosslinking had a significant effect on chain scission. After the second stage, these nanofibers showed residue weight of approximately $6-9 \%$. However, the final residue weight at $600^{\circ} \mathrm{C}$ was not affected from sole heat fixation. For PVABTCA-130, PVA-BTCA-150 and PVA-BTCA-170 nanofibers, elimination reactions started at approximately 225, 237 and $223^{\circ} \mathrm{C}$ and chain-scission reactions started at approximately 352,352 and $325^{\circ} \mathrm{C}$, leaving 46,46 and $51 \%$ residue weight, respectively. These results confirm that an increase in thermal stability is a direct consequence of crosslinking with BTCA, and when compared to BTCA crosslinking is more effective than heat fixation self-crosslinking.

\subsection{SEM images of PVA and PVA-BTCA nanofibers}

The surface morphology of electrospun nanofibers of neatPVA and PVA-BTCA was investigated by SEM imaging. Bead free, uniform PVA and PVA-BTCA nanofibers were produced

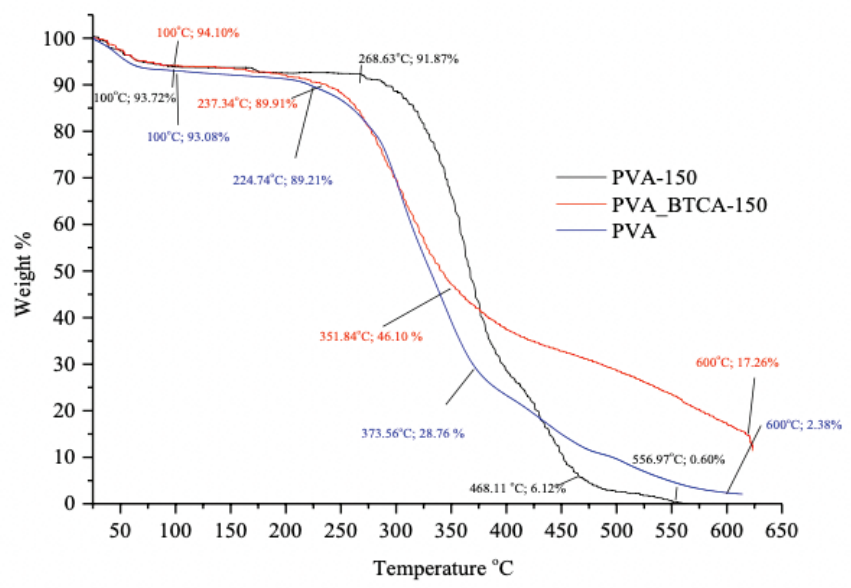

Figure 3. TGA thermograms of $10 \mathrm{~h}$ produced neat-PVA, PVA-150 and PVA-BTCA-150 nanofibers.

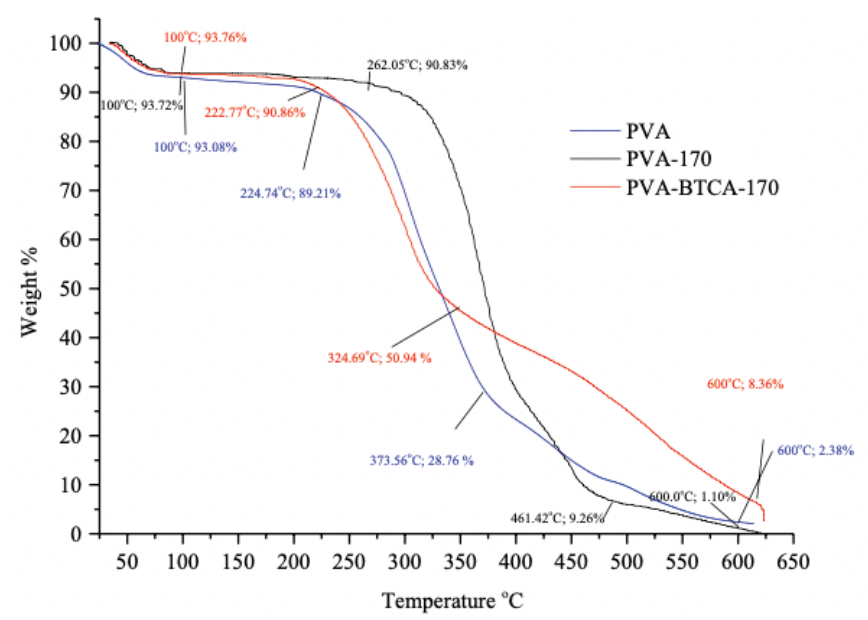

Figure 4. TGA thermograms of $10 \mathrm{~h}$ collected neat-PVA, PVA-170 and PVA-BTCA-170 nanofibers. 
Table 1. Weight $\%$ of the electrospun neat-PVA and 130,150 and $170^{\circ} \mathrm{C}$ heat-fixated PVA and PVA-BTCA nanofibers at given temperatures according to the TGA analyses

\begin{tabular}{|c|c|c|c|c|c|}
\hline & \multicolumn{2}{|c|}{ First stage } & \multicolumn{2}{|c|}{ Second stage } & \multirow{2}{*}{$\begin{array}{c}600^{\circ} \mathrm{C} \\
\text { Residue }(\% \text { weight })\end{array}$} \\
\hline & Temperature $\left({ }^{\circ} \mathrm{C}\right)$ & $\begin{array}{c}\text { Residue (\% } \\
\text { weight) }\end{array}$ & Temperature $\left({ }^{\circ} \mathrm{C}\right)$ & $\begin{array}{c}\text { Residue (\% } \\
\text { weight) }\end{array}$ & \\
\hline Neat-PVA & 225 & 89.21 & 374 & 28.76 & 2.38 \\
\hline PVA-130 & 281 & 90.14 & 477 & 8.59 & 0.18 \\
\hline PVA-150 & 269 & 91.87 & 468 & 6.12 & 0.60 \\
\hline PVA-170 & 262 & 90.83 & 461 & 9.26 & 2.38 \\
\hline PVA-BTCA-130 & 225 & 90.55 & 352 & 46.10 & 14.05 \\
\hline PVA-BTCA-150 & 237 & 89.91 & 352 & 46.10 & 17.26 \\
\hline PVA-BTCA-170 & 223 & 90.86 & 325 & 50.94 & 8.36 \\
\hline
\end{tabular}

(Figure 5). Mean fiber diameters of the neat-PVA and PVABTCA nanofibers were approximately 328.9 and $272.36 \mathrm{~nm}$, respectively, and as expected, any change in nanofiber diameters was not observed depending on the collection time. Differences in the fiber diameters were analyzed by one-way ANOVA. It was observed that the difference between the neatPVA and PVA-BTCA nanofiber diameters was statistically significant $(p<0.05)$. PVA-BTCA nanofibers were thinner than PVA nanofibers due to the conductivity of the BTCA-added solutions. The addition of BTCA significantly increases the solution conductivity because of the acidic nature [34].

\subsection{Thickness and weight per square meter of the neat- PVA and PVA-BTCA nanofibers}

Table 2 lists the mean thickness and weight of the neat-PVA and PVA-BTCA nanofibers. Heat fixation did not have an effect on these data; thus, they were given according to the collection periods. As expected, the thickness and weight of the nanofiber mats were significantly affected by the collection period, and the thickness of the neat-PVA nanofiber mats was more than that of the PVA-BTCA nanofibers due to their thicker nanofiber diameter.

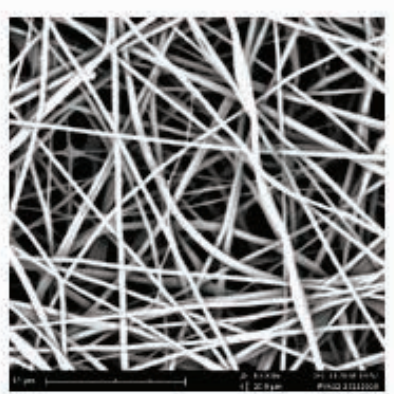

a

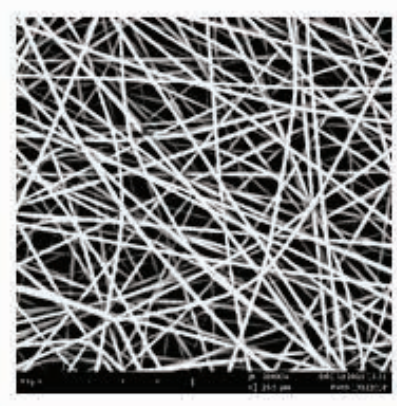

b
Figure 5. SEM images of (a) neat-PVA and (b) PVA-BTCA nanofibers.
Table 2. Thickness and weight of the electrospun neat-PVA and PVABTCA nanofibers

\begin{tabular}{|c|c|c|}
\hline & $\begin{array}{c}\text { Mean thickness } \\
(\mathbf{m m}) \pm \mathbf{S D}\end{array}$ & $\begin{array}{c}\text { Mean weight } \\
\left(\mathbf{g} / \mathbf{m}^{2}\right) \pm \mathbf{S D}\end{array}$ \\
\hline PVA $-3 \mathrm{~h}$ & $0.076 \pm 0.020$ & $17.84 \pm 0.62$ \\
\hline PVA -5 h & $0.149 \pm 0.025$ & $34.32 \pm 3.89$ \\
\hline PVA -10 h & $0.180 \pm 0.024$ & $38.80 \pm 1.31$ \\
\hline PVA-BTCA - 3 h & $0.029 \pm 0.010$ & $8.99 \pm 1.10$ \\
\hline PVA-BTCA - 5 h & $0.085 \pm 0.020$ & $20.92 \pm 2.33$ \\
\hline PVA-BTCA - 10 h & $0.140 \pm 0.020$ & $28.65 \pm 5.92$ \\
\hline
\end{tabular}

\subsection{Swelling and weight loss of nanofibrous mats}

Swelling and weight loss of the neat-PVA and PVA-BTCA nanofibers are given in Figure 6 according to the heat fixation temperatures. Without BTCA, the degree of swelling of PVA nanofibers was : was $\sim 4000 \%$ for the heat fixation temperatures of 130 and $150^{\circ} \mathrm{C}$, while the percentage of weight loss was as much as $\sim 82-96 \%$. However, when the heat fixation temperature was increased to $170^{\circ} \mathrm{C}$, swelling of the nanofibers significantly decreased to $690 \%$ and weight loss to $15 \%$ due to the self-crosslinking of PVA with heat [32]. BTCA crosslinking led to a significant decrease in the degree of swelling at $150^{\circ} \mathrm{C}$. It was $\sim 650 \%$, and weight loss of the PVA-BTCA- 150 nanofibers was $8 \%$. Slight swelling of the nanofibrous structure occurred with negligible weight loss. However, for PVA-BTCA130 nanofibers, swelling of the mats was $\sim 2500 \%$, while weight loss was $\sim 41 \%$, which means $130^{\circ} \mathrm{C}$ was not enough for crosslinking. Swelling and weight loss of PVA-BTCA-170 nanofibers were close to those of PVA-150 nanofibers and showed that they were cross-linked properly.

\subsection{Pore size analysis}

To compare the pore size of the neat-PVA and PVA-BTCA nanofibers mats according to their collection period, the vertical capillary method was performed by capillary flow porometry. It provides a better understanding of water penetration on the 


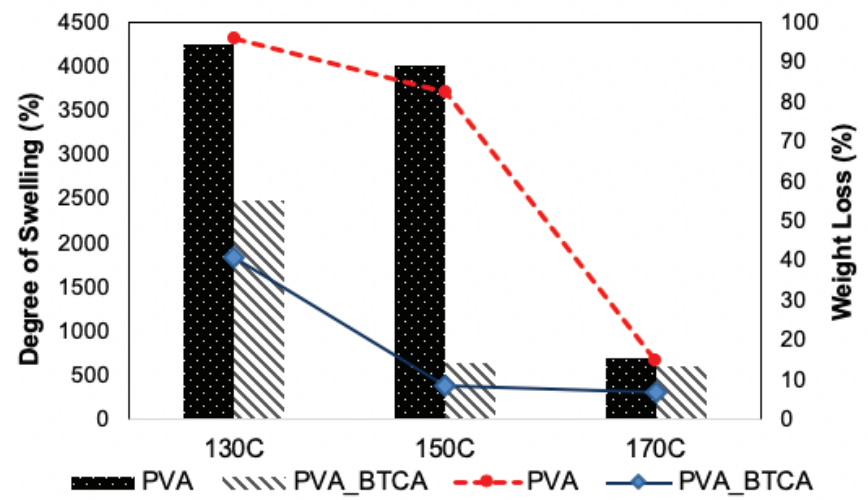

Figure 6. Swelling and weight loss of $10 \mathrm{~h}$ collected neat-PVA and PVA-BTCA nanofibers after heat fixation at 130,150 and $170^{\circ} \mathrm{C}$.

surface since this method takes the whole structure of the nanofibers into account [35].

The FBP, the MFP and the smallest pore size are given in Table 3. A decrease in the mean nanofiber diameter of PVA-BTCA nanofibers did not cause a significant effect on the pore sizes; they were close to that of the neat-PVA nanofibers. The FBP was in the range of 2.01-2.45 and 2.05-2.34, and the MFP was in the range of $1.05-1.33$ and $1.26-1.32$ for the neatPVA and PVA-BTCA nanofibers, respectively. The effect of the electrospun membrane thickness on the pore size can be explained by depositing more fibers on the substrate, which results in smaller pores when other variables (such as fiber diameter and fiber length) are kept constant. However, the mean pore size reached an asymptotic level with the increase in mat thickness [36]. In our case, the membrane thicknesses of both the neat-PVA and PVA-BTCA nanofibers were too high and did not play an important role in reducing the pore size. There was not any statistical difference $(p<0.05)$. According to these results, to achieve smaller pore sizes, there is no need to extent the collection period to 5 or $10 \mathrm{~h}$. In all, $3 \mathrm{~h}$ of collections with thickness of $0.029-0.079 \mathrm{~mm}$ is enough for approximately $1 \mu \mathrm{m}$ MFP.

\subsection{Adsorption results}

In this study, 3, 5 and $10 \mathrm{~h}$ collected neat-PVA and PVABTCA nanofiber mats and heat was fixated at 130, 150 and $170^{\circ} \mathrm{C}$. Then, these nanofibrous mats were evaluated for the color removal of Reactive Red 141. The dye adsorption onto the neat-PVA and PVA-BTCA nanofiber mats was studied as a function of contact time, and the adsorption results are presented in Figure 7.

The adsorption capacity $(q)$ increased in time but reached the plateau at the same time (approximately 4-6 h) for different collection times and fixation temperatures. The maximum equilibrium adsorption capacities of the nanofiber membranes after $48 \mathrm{~h}$ were equal to 84.36 and $87.40 \mathrm{mg} / \mathrm{g}$ for $150^{\circ} \mathrm{C}$ heatfixated neat-PVA and PVA-BTCA nanofibers, respectively.

It was observed that there was no significant difference between the neat-PVA and PVA-BTCA nanofiber mats in mean values of adsorption properties. The results of adsorption experiments also showed that collection periods did not significantly affected the adsorbed amount of the dye, they were close to each other. Thus, adsorption capabilities of PVA nanofibers did not rely on the thickness of the PVA mats, and 3 -h collection period was enough for the dye adsorption. However, it was seen that fixation temperature had a significant effect on the dye adsorption. The adsorbed amount of the dye reached the highest and the lowest adsorption rates at $150^{\circ} \mathrm{C}$ and $130^{\circ} \mathrm{C}$, respectively. According to these results, $130^{\circ} \mathrm{C}$ was not enough and $170^{\circ} \mathrm{C}$ was too much for the higher adsorption amounts. In all, $150^{\circ} \mathrm{C}$ of fixation temperature was the most suitable temperature for both the neat-PVA and PVA-BTCA nanofiber mats. These results were also noticeable in the color of the dye solutions after the adsorption process (Figure 8).

In order to evaluate the morphology of the nanofibers after the adsorption process, SEM images of the nanofibers were taken. In Figure 9, PVA-130 nanofibers were not stable in water; they almost lost their fibrous structure. With the increasing temperature, PVA nanofibers had better preserved their fibrous structure. Although in case of $150^{\circ} \mathrm{C}$, PVA-150 nanofiber mats shrunk and nanofibers were entangled. PVA-170 nanofibers were still straight and in a nanofiber form when compared to PVA-150. Adsorption of dye aggregates and particles of $\mathrm{Na}_{2} \mathrm{SO}_{4}$ and $\mathrm{Na}_{2} \mathrm{CO}_{3}$ could be also seen for both PVA-150 and PVA-170 nanofibers. On the other hand, BTCA crosslinking significantly improved the water stability of the PVA nanofibers when compared to that of heat-fixated neat-PVA nanofibers. Even at $130^{\circ} \mathrm{C}$, nanofibers preserved their fibrous structure. In all three cases, adsorption of dye aggregates and particles of $\mathrm{Na}_{2} \mathrm{SO}_{4}$ and $\mathrm{Na}_{2} \mathrm{CO}_{3}$ could be seen on the surfaces of nanofibers. However, it could be clearly seen from the SEM images that dye aggregates and particles of $\mathrm{Na}_{2} \mathrm{SO}_{4}$ and $\mathrm{Na}_{2} \mathrm{CO}_{3}$ were also penetrated inside the fibrous structure, so it

Table 3. Pore size measurement results of the electrospun neat-PVA and PVA-BTCA nanofibers

\begin{tabular}{|c|c|c|c|}
\hline & FBP $(\boldsymbol{\mu m})$ & MFP $(\mu \mathrm{m})$ & Smallest pore size $(\boldsymbol{\mu m})$ \\
\hline PVA $-3 \mathrm{~h}$ & $2.45 \pm 0.48$ & $1.33 \pm 0.17$ & $0.64 \pm 0.19$ \\
\hline PVA $-5 \mathrm{~h}$ & $2.01 \pm 0.09$ & $1.05 \pm 0.01$ & $0.56 \pm 0.02$ \\
\hline PVA-10 h & $2.02 \pm 0.15$ & $1.07 \pm 0.08$ & $0.56 \pm 0.08$ \\
\hline PVA-BTCA $-3 \mathrm{~h}$ & $2.05 \pm 0.31$ & $1.32 \pm 0.17$ & $0.88 \pm 0.48$ \\
\hline PVA-BTCA $-5 \mathrm{~h}$ & $2.34 \pm 0.06$ & $1.31 \pm 0.12$ & $0.63 \pm 0.00$ \\
\hline PVA-BTCA $-10 \mathrm{~h}$ & $2.23 \pm 0.06$ & $1.26 \pm 0.19$ & $0.70 \pm 0.15$ \\
\hline
\end{tabular}


PVA

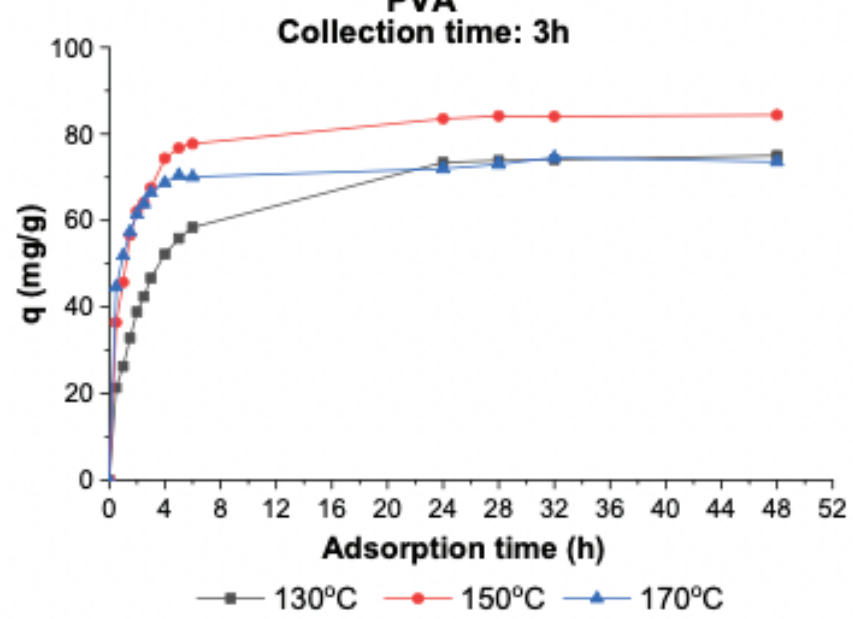

PVA

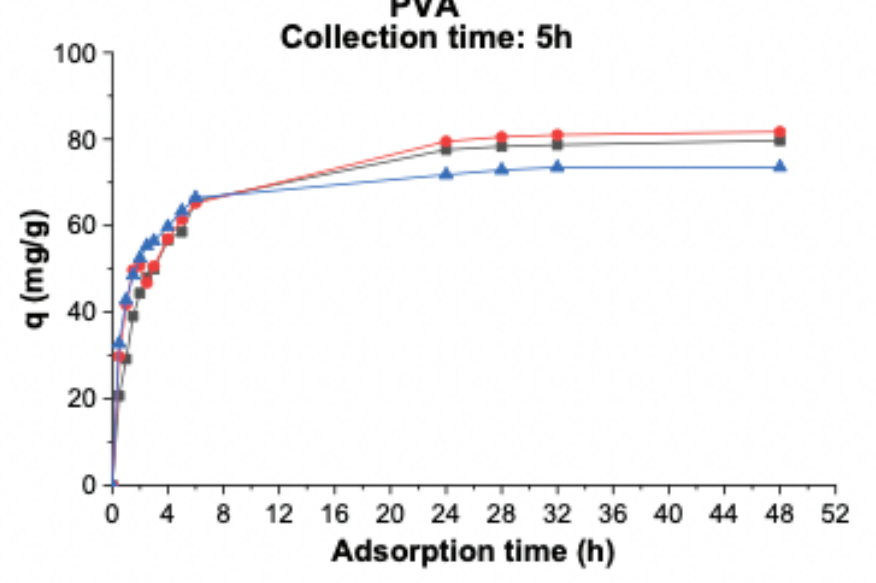

$\rightarrow 130^{\circ} \mathrm{C} \longrightarrow 150^{\circ} \mathrm{C} \longrightarrow 170^{\circ} \mathrm{C}$

PVA

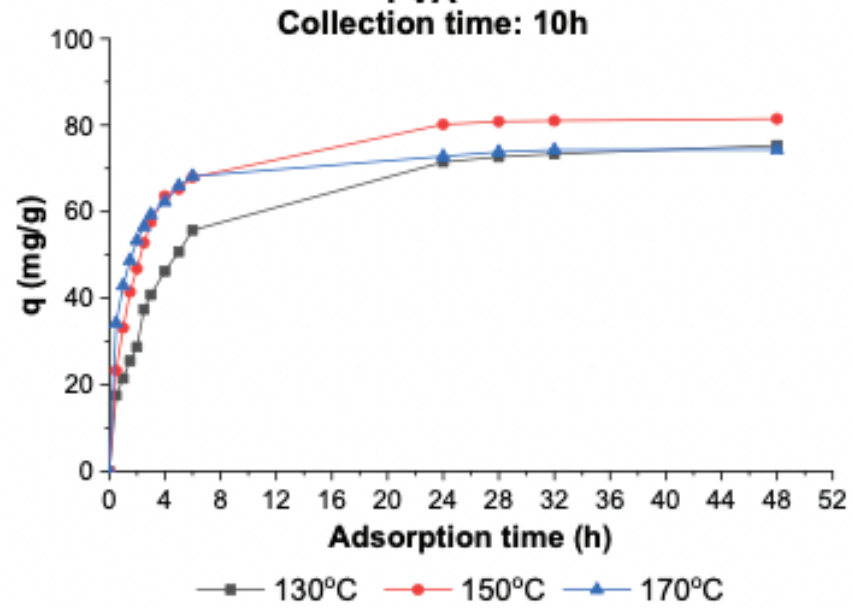

PVA-BTCA

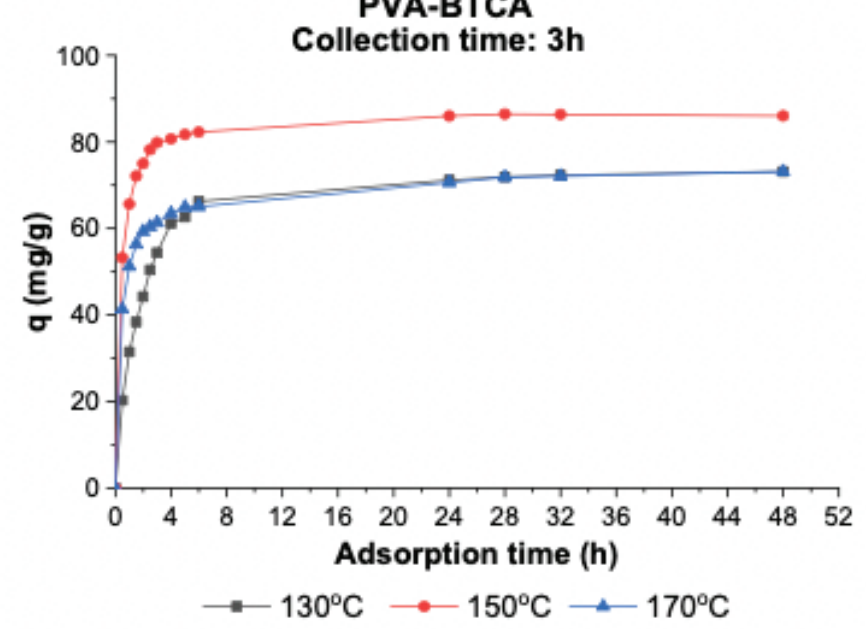

PVA-BTCA

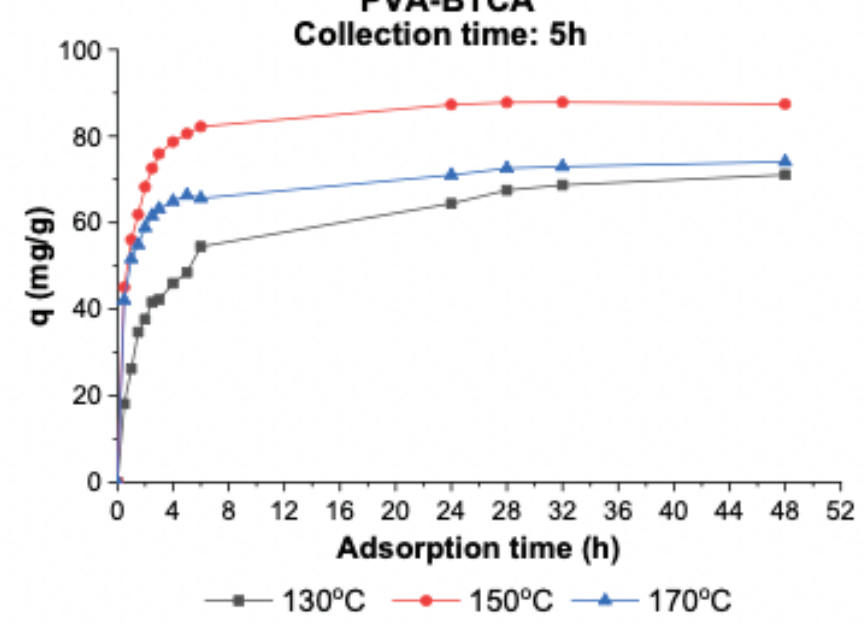

PVA-BTCA

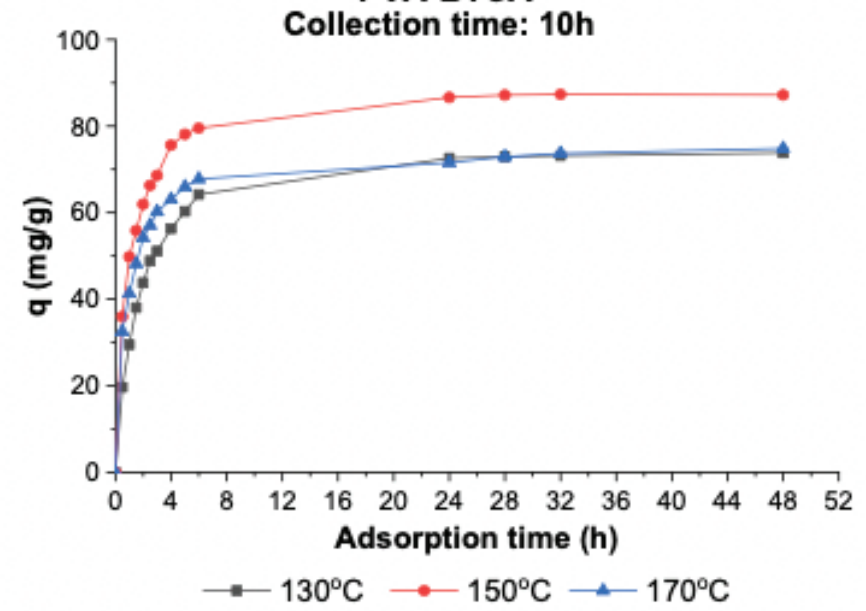

Figure 7. Amounts of the dye adsorbed versus contact time for PVA and PVA-BTCA nanofibers produced in different collection times and fixation temperatures.

could be said that preserving the nanofibrous structure has an impact on adsorption of these aggregates and particles.

It was clear from the SEM images of the nanofibers after the adsorption process (Figure 9) and weight loss test results (Figure 6) that PVA nanofibers were not stable to water at 130 and $150^{\circ} \mathrm{C}$. Thus, to remove the color from the wastewater, PVA nanofibers could be used but PVA nanofibers should be chemically cross-linked properly. According to these results, $150^{\circ} \mathrm{C}$ heat-fixated PVA-BTCA nanofibers mats are convenient for this application. 


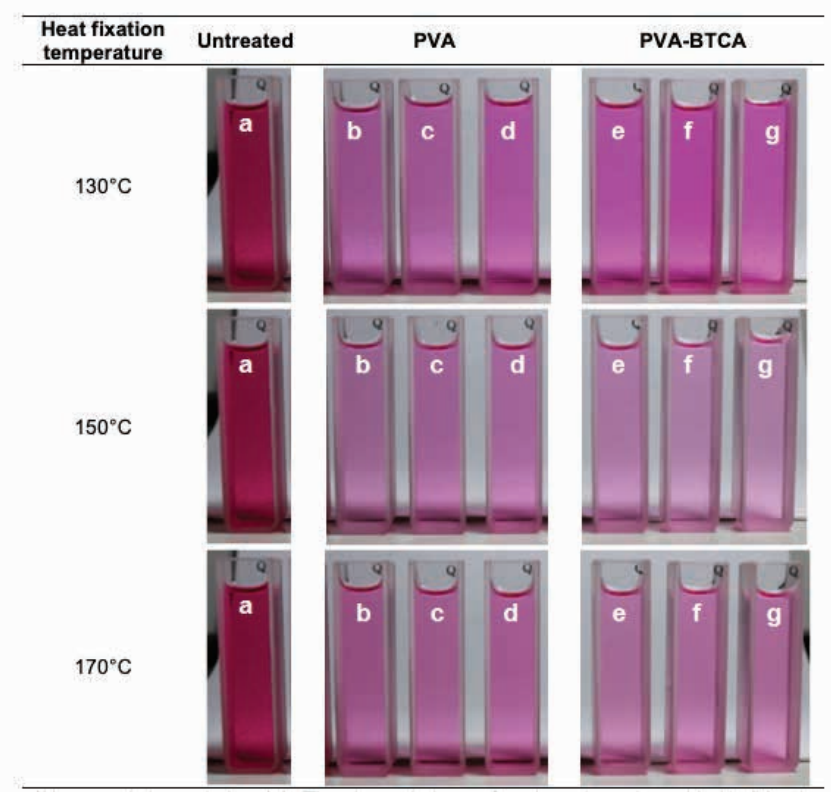

Figure 8. Images of the dye baths before and after the adsorption process. *Untreated dye solution (a). The dye solutions after the adsorption with $3 \mathrm{~h}(\mathrm{~b}), 5 \mathrm{~h} \mathrm{(c)} \mathrm{and} 10 \mathrm{~h}$ (d) collected and heat-fixated neat-PVA nanofibers; The dye solutions after the adsorption with $3 \mathrm{~h}(\mathrm{e})$, $5 \mathrm{~h}(\mathrm{f})$ and $10 \mathrm{~h}(\mathrm{~g})$ collected and heat-fixated PVA-BTCA nanofibers.

Table 4. Parameters of the pseudo-first-order equation
The pseudo-first-order kinetic equation (Equation 3) and pseudo-second-order kinetic equation (Equation 5) were also applied to the adsorption data. The parameters of the kinetic models and correlation coefficients are given in Tables 4 and 5 . The values of the correlation coefficient implied that the adsorption of the dye on the neat-PVA and PVA-BTCA nanofibers was described by a pseudo-second-order equation.

\section{Conclusion}

In this study, neat-PVA and PVA-BTCA nanofibers were produced by electrospinning method for the adsorption of Reactive Red 141. TGA was used to evaluate the thermal degradation of the nanofibers versus temperature. TGA results confirm that an increase in thermal stability is a direct consequence of crosslinking with BTCA, and when they were compared with neat-PVA nanofibers, BTCA crosslinking is more effective than heat fixation/self-crosslinking. Mean fiber diameters of the neat-PVA and PVA-BTCA nanofibers were approximately 328.9 and $272.36 \mathrm{~nm}$, respectively, and it was considered to be statistically significant $(p<0.05)$. The thicknesses of the nanofiber mats significantly affected by the collection period and the thinner PVA-BTCA nanofiber

\begin{tabular}{|c|c|c|c|c|c|}
\hline Polymer & Collection time (h) & Fixation temperature $\left({ }^{\circ} \mathrm{C}\right)$ & $q_{e}$ & $k^{1}\left(s^{-1}\right)$ & $R^{2}$ \\
\hline \multirow{9}{*}{ PVA } & \multirow{3}{*}{3} & $130^{\circ}$ & 76.92 & 91.42 & 0.85 \\
\hline & & $150^{\circ}$ & 95.24 & 54.67 & 0.73 \\
\hline & & $170^{\circ}$ & 82.65 & 30.59 & 0.47 \\
\hline & \multirow{3}{*}{5} & $130^{\circ}$ & 87.72 & 105.16 & 0.90 \\
\hline & & $150^{\circ}$ & 82.65 & 59.17 & 0.73 \\
\hline & & $170^{\circ}$ & 80.65 & 49.26 & 0.69 \\
\hline & \multirow{3}{*}{10} & $130^{\circ}$ & 71.43 & 110.79 & 0.85 \\
\hline & & $150^{\circ}$ & 91.74 & 95.40 & 0.89 \\
\hline & & $170^{\circ}$ & 81.97 & 48.03 & 0.68 \\
\hline \multirow{9}{*}{ PVA-BTCA } & \multirow{3}{*}{3} & $130^{\circ}$ & 87.72 & 103.93 & 0.91 \\
\hline & & $150^{\circ}$ & 98.04 & 28.63 & 0.44 \\
\hline & & $170^{\circ}$ & 80.00 & 32.06 & 0.49 \\
\hline & \multirow{3}{*}{5} & $130^{\circ}$ & 73.53 & 98.49 & 0.89 \\
\hline & & $150^{\circ}$ & 99.00 & 41.15 & 0.61 \\
\hline & & $170^{\circ}$ & 80.65 & 32.00 & 0.49 \\
\hline & \multirow{3}{*}{10} & $130^{\circ}$ & 86.21 & 106.98 & 0.91 \\
\hline & & $150^{\circ}$ & 99.00 & 57.32 & 0.75 \\
\hline & & $170^{\circ}$ & 82.65 & 52.24 & 0.71 \\
\hline
\end{tabular}




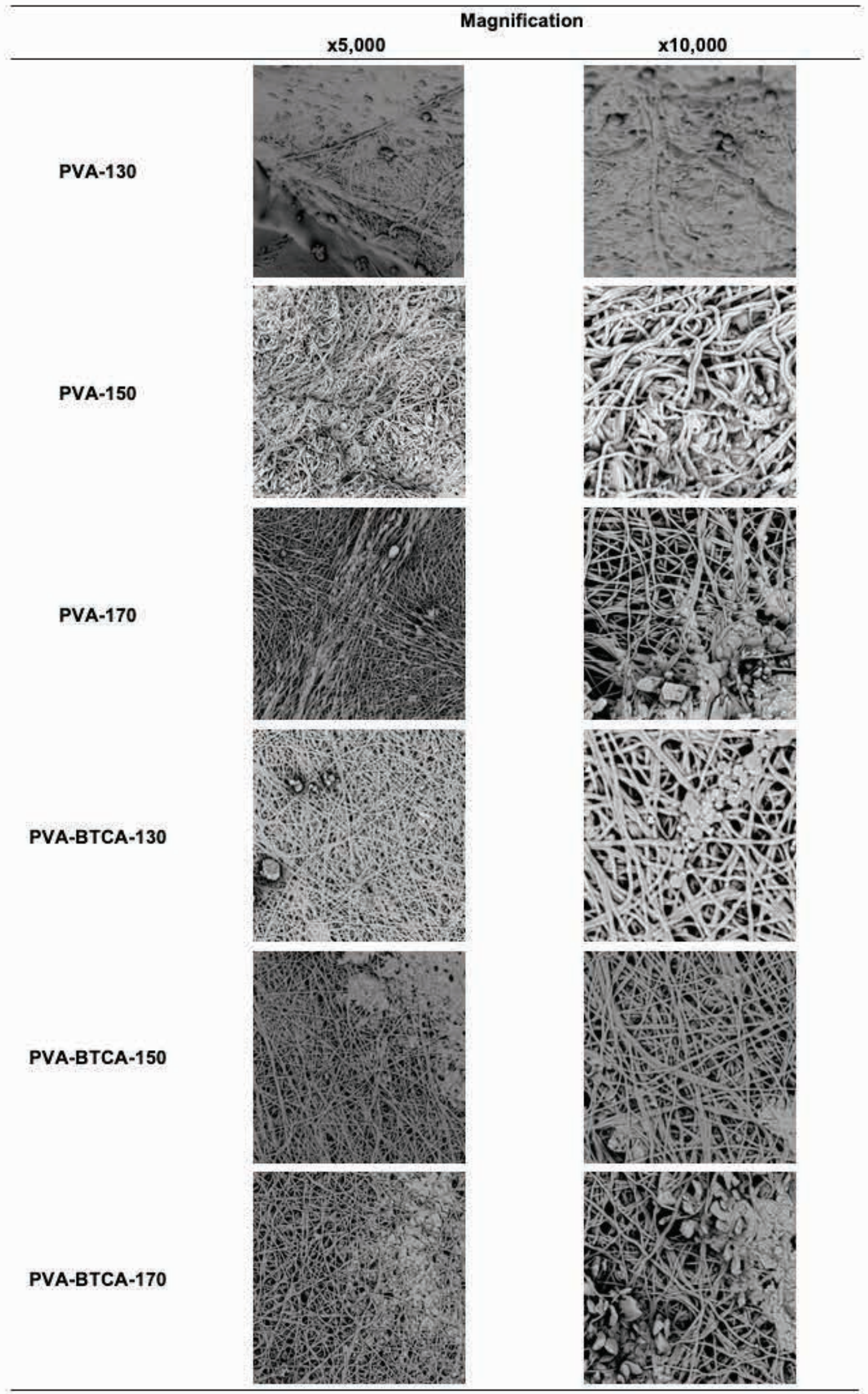

Figure 9. SEM images of the heat-fixated neat-PVA and PVA-BTCA nanofibers after adsorption studies. 
Table 5. Parameters of the pseudo-second-order equation

\begin{tabular}{|c|c|c|c|c|c|}
\hline Polymer & Collection time $(\mathrm{h})$ & Fixation temperature $\left({ }^{\circ} \mathrm{C}\right)$ & $q_{e}\left(m g \cdot g^{-1}\right)$ & $\mathrm{k}_{2}\left(\mathrm{dm}^{3} \cdot \mathrm{mol}^{-1} \cdot \mathrm{s}^{-1}\right)$ & $R^{2}$ \\
\hline \multirow{9}{*}{ PVA } & \multirow{3}{*}{3} & $130^{\circ}$ & 82.65 & 0.00011 & 0.98 \\
\hline & & $150^{\circ}$ & 87.72 & 0.00028 & 0.99 \\
\hline & & $170^{\circ}$ & 75.76 & 0.00060 & 0.99 \\
\hline & \multirow{3}{*}{5} & $130^{\circ}$ & 86.96 & 0.00012 & 0.99 \\
\hline & & $150^{\circ}$ & 86.96 & 0.00014 & 0.99 \\
\hline & & $170^{\circ}$ & 76.92 & 0.00028 & 0.99 \\
\hline & \multirow{3}{*}{10} & $130^{\circ}$ & 86.21 & 0.00007 & 0.96 \\
\hline & & $150^{\circ}$ & 87.72 & 0.00014 & 0.99 \\
\hline & & $170^{\circ}$ & 77.52 & 0.00030 & 0.99 \\
\hline \multirow{9}{*}{ PVA-BTCA } & \multirow{3}{*}{3} & $130^{\circ}$ & 78.13 & 0.00019 & 0.99 \\
\hline & & $150^{\circ}$ & 87.72 & 0.00070 & 0.99 \\
\hline & & $170^{\circ}$ & 74.63 & 0.00045 & 0.99 \\
\hline & \multirow{3}{*}{5} & $130^{\circ}$ & 76.92 & 0.00012 & 0.98 \\
\hline & & $150^{\circ}$ & 90.09 & 0.00037 & 0.99 \\
\hline & & $170^{\circ}$ & 75.19 & 0.00045 & 0.99 \\
\hline & \multirow{3}{*}{10} & $130^{\circ}$ & 79.37 & 0.00016 & 0.99 \\
\hline & & $150^{\circ}$ & 90.91 & 0.00025 & 0.99 \\
\hline & & $170^{\circ}$ & 77.52 & 0.00029 & 0.99 \\
\hline
\end{tabular}

mats were produced due to finer nanofiber diameter. BTCA crosslinking led to a significant decrease in the degree of swelling at $150^{\circ} \mathrm{C}$. It was $\sim 650 \%$, and weight loss of the PVA150 nanofibers was $8 \%$. A slight swelling of the nanofibrous structure occurred with negligible weight loss. According to pore size evaluation, to achieve smaller pore sizes, $3 \mathrm{~h}$ of collection with a thickness of 0.029-0.079 mm was enough for $\sim 1 \mu \mathrm{m}$ MFP. From the adsorption studies, it was seen that the neat-PVA nanofibers could be used for the removal of reactive dye color. However, PVA nanofibers should be chemically cross-linked properly. When the fixation temperatures of 130 , 150 and $170^{\circ} \mathrm{C}$ were compared, $150^{\circ} \mathrm{C}$ was the most suitable temperature in case of adsorption and water stability results.

\section{References}

[1] Grand View Research Reports, "Dyes and Pigments Market Size, Share I Industry Analysis Report, 2025," 2019. [Online]. Available: https://www.grandviewresearch.com/ industry-analysis/dyes-and-pigments-market. [Accessed: 14-Jan-2019].

[2] Sharma, S. K. (2015). Green Chemistry for Dyes Removal from Wastewater-Research Trends and Applications. New Jersey: Scrivener Publishing.
[3] Singh, K., Arora, S. (2011). Removal of synthetic textile dyes from wastewaters: A critical review on present treatment technologies. Critical Reviews in Environmental Science and Technology, 41(9), 807-878.

[4] Forgacs, E., Cserháti, T., Oros, G. (2004). Removal of synthetic dyes from wastewaters: A review. Environment International, 30(7), 953-971.

[5] Al-Ghouti, M. A., Khraisheh, M. A., Allen, S. J., Ahmad M. $N$. (2003). The removal of dyes from textile wastewater: a study of the physical characteristics and adsorption mechanisms of diatomaceous earth. The Journal of Environmental Management, 69, 229-238.

[6] Mukherjee, A. K., Gupta, B., Chowdhury, S. M. S. (1999). Separation of dyes from cotton dyeing effluent using cationic polyelectrolytes. American Dyestuff Reporter, 88(2), 25-28.

[7] J. Shore and C. Society of Dyers and, "Cellulosics dyeing," p. ix,408p., 1995.

[8] Dolphen, R., Sakkayawong, N., Thiravetyan, P., Nakbanpote, W. (2007). Adsorption of Reactive Red 141 from wastewater onto modified chitin. Journal of Hazardous Materials, 145(1-2), 250-255. 
[9] Abdouss, M., Shoushtari, A. M., Haji, A., Moshref, B. (2012). Fabrication of chelating diethylenetriaminated pan micro-and nano-fibers for heavy metal removal. Chemical Industry and Chemical Engineering Quarterly, 18(1), 2734.

[10] Abdouss, M., Mousavi Shoushtari, A., Majidi Simakani, A., Akbari, S., Haji, A. (2014). Citric acid-modified acrylic micro and nanofibers for removal of heavy metal ions from aqueous media. Desalination and Water Treatment, 52(37-39), 7133-7142.

[11] Haji, A., Mahmoodi, N. M. (2012). Soy meal hull activated carbon: preparation, characterization and dye adsorption properties. Desalination and Water Treatment, 44(1-3), 237-244.

[12] Llewellyn, P., Maurin, G., Rouquerol, J. (2014). Adsorption by Powders and Porous Solids.

[13] Aliabadi, M., Irani, M., Ismaeili, J., Piri, H., Parnian, M. J. (2013). Electrospun nanofiber membrane of PEO/ Chitosan for the adsorption of nickel, cadmium, lead and copper ions from aqueous solution. Chemical Engineering Journal, 220, 237-243.

[14] Elemen, S., Akçakoca Kumbasar, E. P., Yapar, S. Modeling the adsorption of textile dye on organoclay using an artificial neural network. Dyes and Pigment, 95(1), 102-111, 2012.

[15] Kumari, K., Abraham, T. E. (2007). Biosorption of anionic textile dyes by nonviable biomass of fungi and yeast. Bioresource Technology, 98(9), 1704-1710.

[16] Salleh, M. A. M., Mahmoud, D. K., Karim, W. A. W. A., Idris, A. (2011). Cationic and anionic dye adsorption by agricultural solid wastes: A comprehensive review. Desalination, 280(1-3), 1-13.

[17] Akduman, C., Akçakoca Kumbasar, E. P., Morsunbul, S. (2017). Electrospun nanofiber membranes for adsorption of dye molecules from textile wastewater. IOP Conference Series: Materials Science and Engineering, 254(10), 102001.

[18] Bhaumik, M., McCrindle, R., Maity, A. (2013). Efficient removal of Congo red from aqueous solutions by adsorption onto interconnected polypyrrole-polyaniline nanofibres. Chemical Engineering Journal, 228, 506-515.

[19] Ramakrishna, S., Fujihara, K., Teo, W.-E., Lim, T.-C., Ma, Z. (2005). An Introduction to Electrospinning and Nanofibers. World Scientific.

[20] Adabi, M., Saber, R., Faridi-Majidi, R., Faridbod, F. (2015). Performance of electrodes synthesized with polyacrylonitrile-based carbon nanofibers for application in electrochemical sensors and biosensors. Materials Science and Engineering C, 48, 673-678.

[21] Huang, Z.-M., Zhang, Y.-Z., Kotaki, M., Ramakrishna, S. (2003). A review on polymer nanofibers by electrospinning and their applications in nanocomposites. Composites Science and Technology, 63(15), 2223-2253.

[22] Wang, B., Wang, Y., Yin, T., Yu, Q. (2010). Applications of electrospinning technique in drug delivery. Chemical Engineering Communications, 197(10), 1315-1338.

[23] Sill, T. J., von Recum, H. A. (2008). Electrospinning: Applications in drug delivery and tissue engineering. Biomaterials, 29(13), 1989-2006.

[24] Teo, W. E., Ramakrishna, S. (2006). A review on electrospinning design and nanofibre assemblies. Nanotechnology, 17(14), R89-R106.
[25] Deng, J., Kang, X., Chen, L., Wang, Y., Gu, Z., Lu, Z. (2011). A nanofiber functionalized with dithizone by coelectrospinning for lead (II) adsorption from aqueous media. Journal of Hazardous Materials, 196, 187-193.

[26] Tian, Y., Min Wu, Ruigang Liu, Yanxiang Li, Deqian Wang et al. (2011). Electrospun membrane of cellulose acetate for heavy metal ion adsorption in water treatment. Carbohydrate Polymers, 83(2), 743-748.

[27] Wu, S., Li, F., Wang, H., Fu, L., Zhang, B., Li, G. (2010). Effects of poly (vinyl alcohol) (PVA) content on preparation of novel thiol-functionalized mesoporous PVA/ SiO2composite nanofiber membranes and their application for adsorption of heavy metal ions from aqueous solution. Polymer (Guildf), 51(26), 6203-6211.

[28] Saeed, K., Haider, S., Oh, T.-J., Park, S.-Y. (2008). Preparation of amidoxime-modified polyacrylonitrile (PANoxime) nanofibers and their applications to metal ions adsorption. Journal of Membrane Science, 322(2), 400405.

[29] Zhang, L., Menkhaus, T. J., Fong, H. (2008). Fabrication and bioseparation studies of adsorptive membranes/felts made from electrospun cellulose acetate nanofibers. Journal of Membrane Science, 319(1-2), 176-184.

[30] Haider, S., Park, S.-Y. (2009). Preparation of the electrospun chitosan nanofibers and their applications to the adsorption of $\mathrm{Cu}(\mathrm{II})$ and $\mathrm{Pb}(\mathrm{II})$ ions from an aqueous solution. Journal of Membrane Science, 328(1-2), 90-96.

[31] Ding, B., Kimura, E., Sato, T., Fujita, S., Shiratori, S. (2004). Fabrication of blend biodegradable nanofibrous nonwoven mats via multi-jet electrospinning. Polymer (Guildf), 45(6), 1895-1902.

[32] Miraftab, M., Saifullah, A. N., Çay, A. (2015). Physical stabilisation of electrospun poly(vinyl alcohol) nanofibres: comparative study on methanol and heat-based crosslinking. Journal of Materials Science, 50(4), 19431957.

[33] Çay, A., Miraftab, M. (2013). Properties of electrospun poly(vinyl alcohol) hydrogel nanofibers crosslinked with 1,2,3,4-butanetetracarboxylic acid. Journal of Applied Polymer Science, 129(6), 3140-3149.

[34] Akduman, Ç., Kumbasar, E. P. A., Özgüney, I. (2018). Development and characterization of naproxenloaded poly(vinyl alcohol) nanofibers crosslinked with polycarboxylic acids. AATCC Journal of Research, 5(1), 29-38.

[35] Khatri, Z., Wei, K, Kim, B. S., Kim, I. S. (2012). Effect of deacetylation on wicking behavior of co-electrospun cellulose acetate/polyvinyl alcohol nanofibers blend. Carbohydrate Polymers, 87(3), 2183-2188.

[36] Liu, Y., Wang, R., Ma, H., Hsiao, B. S., Chu, B. (2013). High-flux microfiltration filters based on electrospun polyvinylalcohol nanofibrous membranes. Polymer (Guildf), 54(2), 548-556.

[37] Aljeboree, A. M., Alshirifi, A. N., Alkaim, A. F. (2017). Kinetics and equilibrium study for the adsorption of textile dyes on coconut shell activated carbon. Arabian Journal of Chemistry, 10, S3381-S3393.

[38] N. Ucar, Z. Cavdar, N. Karatepe, P. Altay, and N. Kizildag. (2016). SO2 adsorption capability of activated carbon nanofibers produced by different activation process parameters. Tekstil Ve Konfeksiyon, 26(4), 407-413. 
[39] Teng, M., Qiao, J., Li, F., Bera, P. K. (2012). Electrospun mesoporous carbon nanofibers produced from phenolic resin and their use in the adsorption of large dye molecules. Carbon New York, 50(8), 2877-2886.

[40] Zhu, X., Jiang, X., Cheng, S., Wang, K., Mao, S., Fan, L. J. (2010). Preparation of high strength ultrafine polyvinyl chloride fibrous membrane and its adsorption of cationic dye. Journal of Polymer Research, 17(6), 769-777.

[41] Mahmoodi, N. M., Mokhtari-Shourijeh, Z. (2015). Preparation of PVA-chitosan blend nanofiber and its dye removal ability from colored wastewater. Fibers and Polymers, 16(9), 1861-1869.
[42] Mahanta, N., Valiyaveettil, S. (2011). Surface modified electrospun poly(vinyl alcohol) membranes for extracting nanoparticles from water. Nanoscale, 3(11), 4625-4631.

[43] Qin, X.-H., Wang, S.-Y. (2008). Electrospun nanofibers from crosslinked poly(vinyl alcohol) and its filtration efficiency. Journal of Applied Polymer Science, 109(2), 951-956. 